\title{
STUDI KORELASI BAB: TALQIINAL-MUHTADHAR "LAA ILAHA ILLALLAH" DALAM KITAB "RIYADHUS SHOLIHIN" DENGAN TAUHID ULUHIYAH
} (Studi Kualitatif Analisa Konten)

\author{
Muhammad Nur Ihsan \\ Program Studi Ilmu hadits \\ Sekolah Tinggi Dirasat Islamiyah Imam Syafi'i Jember \\ mnurihsan04@gmail.com
}

\begin{abstract}
The book "Riyadhus Sholihin" is a monumental work written by one of the great scholars who has a high reputation among the Muslims, namely Imam Nawawi. Although the main topic of the book is about encouragement and warningsand also purification of the self, the book also includes themes of faith and oneness of Allah conceptualized by the author in separate chapters accompanied by the arguments from the Qur'an and hadiths, including the Chapters Talqin "al-Muhtadhar" LaallaahaIllallah. Then, how is the correlation of the hadiths that he presented with this chapter and with the tawhid uluhiyyah 'oneness of worship'? This qualitative research paper attempts to answer these questions using the library research method with a content analysis approach. The discussion of this paper is divided into several sub-sections: introduction, brief biography of Imam Nawawi, the meaning of tawhid uluhiyyah, the chapter Talqin and the correlation of the chapter and its arguments with tauhid uluhiyyah, and conclusions, including the following conclusions: (1) Riyadhus Sholihin is not a mere hadith book that discusses the themes of encouragement and warnings and purification of the self, but also contains theme on faith, (2) Imam Nawawi's foresight in conceptualizing the chapters of the book and selecting related arguments withinthem, (3) The correlation between chapter Talqin "al-Muhtadhar" Laa Ilaaha Illallah and tawhid uluhiyyah is obvious, because LaallaahaIllallah is a tawhid proposition which content is the obligation to give worship only to Allah, that is the essence of tawhid uluhiyyah, (4) The correlation of two hadiths which arestated in the chapter Talqin "alh-Muhtadhar" Laa Ilaaha Illallah with tawhid uluhiyyahis very firm and clear.
\end{abstract}

Keywords: Correlation, Talqin, Laa Ilaaha Illallah, Tawhid Uluhiyyah.

\section{ABSTRAK}

Kitab "RiyadhusSholihin" adalah sebuah karya monumental yang ditulis oleh salah seorang ulama besar yang memiliki reputasi yang tinggi di kalangan kaum muslimin, yaitu Imam Nawawi. Kendati topik utama kitab tersebut tentang targhib wa tarhiib dan tazkiyatun nufus, kitab itu juga mencakup tema-tema akidah dan tauhid yang dikonsep oleh pengarang dalam bab-bab terpisah disertai dengan dalil-dalil Al-Qur'an dan Hadis, di antaranya Bab Talqin "alh-Muhtadhar" Laa Ilaaha Illallah. Lalu, bagaimana korelasi hadis-hadis yang beliau bawa kandengan bab tersebut dan dengan tauhid uluhiyah? Tulisan sederhana ini berusaha menjawab pertanyaan tersebut dengan menggunakan metode library research dan jenis penelitian kualitatif dengan pendekatan analisa konten. Pembahasan tulisan ini dibagi menjadi beberapa sub bahasan: pendahuluan, biogarafi singkat Imam Nawawi, pengertian tauhid Uluhiyah, Talkin dan studi korelasi bab tersebut beserta dalil-dalilnya dengan tauhid Uluhiyah, dan penutup, mencakup kesimpulan berikut: (1) Kitab Riyadhus Sholihin bukan 
kitab hadis semata yang mengupas tema-tema targhib wa tarhiib dan tazkiyatun nufus, tetapi juga mengandung materi-materi akidah, (2) Kejelian Imam Nawawi dalam mengonsep babbab kitab tersebut dan memilih dalil-dalil yang berkaitan dengannya, (3) Korelasi antara Bab Talqin "al-Muhtadhar" Laa Ilaaha Illallahdengan tauhid uluhiyah sangat nyata, karena Laa Ilaaha Illallah adalah kalimat tauhid yang kandungannya adalah kewajiban mengikhlaskan ibadah kepada Allah, itulah hakikat Tauhid Uluhiyah, (4) Korelasi dua hadis yang dibawakan dalam Bab Talqin "al-Muhtadhar" Laa Ilaaha Illallah dengan tauhid uluhiyah sangat erat dan jelas.

Kata kunci : Korelasi, Talkin, Laa Ilaaha Illallah, Tauhid Uluhiyah.

\section{A. PENDAHULUAN}

Tauhid Uluhiyah adalah hikmah penciptaan manusia, tujuan diutus para rasul dan diturunkan semua kitab, ia adalah perintah yang utama dan kewajiban pertama dalam agama, hakikat makna "Laa Ilaha illallah" dansyarat utama diterima ibadah serta kunci masuk Surga.

Allah Ta'ala telah menjelaskan makna dan hakikat tauhid tersebut didalam Al-Qur'an dengan bermacam redaksi dan argumentasi yang nyata, bahkan sebagian para ulama menyatakan: bahwa setiap surat dalam Al-Qur'an, bahkan setiap ayat didalamnya menyeru kepada tauhid uluhiyah, sebagai bukti kebenaran dan keagungannya, karena kandungan AlQur'an secara global tidak keluar dari subtansi berikut: (1) berita tentang Allah, nama-nama, sifat-sifat dan perbuatan-Nya, ini adalah tauhid Rububiyah dan Tauhid Asma wa sifat yang mencakupdan memestikan tauhid uluhiyah, (2) seruan untuk mengibadati Allah semata, tiada sekutu bagai-Nya, meninggalkan seluruh bentuk kesyirikan, perintah untuk melakukan bermacam ibadah dan keta'atan serta mencegah dari perkara yang terlarang, ini adalah tauhid Uluhiyah atau tauhid Ibadah, (3) mengabarkan tentang kemulian dan kenikmatan yang Allah karuniakan kepada ahli tauhid dan orang-orang yang ta'at di dunia dan akhirat, ini adalah balasan tauhid, (4) mengabarkan tentang pelaku syirik dan azab yang Allah timpakan kepada mereka di dunia dan akhirat, ini adalah sanksipenentangan terhadap tauhid, jadi al-quran seluruhnya berbicara tentang tauhid, hak-haknya dan balasannya, tentang kesyirikan, pelakunya dan sanksibagi mereka (Ibnu Qayyim, 3/468-469 dan Sulaiman bin Abdul Wahhab, 1985: 38-39).

Nabi shalallahu'alaihi wasallam juga telah menjelaskan tauhid uluhiyah dan berbagai permasalahan yang berkaitan dengannya dalam hadis-hadis yang shohih serta telah dipaparkan oleh para ulama ahlussunah wal jama'ah dari berbagai kalangan mazhab dalam karya-karya tulis mereka, baik secara khusus, sebagaimana yang dilakukan oleh Syaikh Muhammad bin Abdul Wahhab (wafat: 1206 H) dalam karya beliau yang sangat monumental, yaitu "Kitab At- 
Tauhid" yang mengupas berbagai perkara tauhid Uluhiyah secara terperinci, atausecara umum dalam kandungan tema-tema dan pembahasan karya tulis mereka, seperti yang dilakukan oleh Imam Nawawi (wafat: $676 \mathrm{H}$ ) dalam bab-bab yang terpisah dalam kitab beliau "Riyadhus Sholihin. "Sebuah karya tulis yang sangat monumental, sarat dengan faedah dan makna, serta penuh dengan berkah dan untaian-untaian mutiara hikmah dari Al-Qur'an dan sunah, banyak dari kalangan ulama islam yang telah mengapresiasinya dan mewasitkan kaum muslimin untuk membacanya, sehingga tidak heran jika kitab tersebut mendapat perhatian luar biasa, dicetak berulang kali dan telah tersebar ditengah kaum muslimin diseluruh pelosok dunia serta diterjemahkan ke dalam berbagai Bahasa (Hasan Al-Halabi, 1421: 5-7). Terlebih lagi pengarangnya, Imam Nawawi adalah salah seorang ulama besar yang memiliki reputasi yang tinggi dan peran yang besar dalam mazhab Syafi'I serta telah mendapatkan rekomendasi dari banyak kalangan ulama, baik yang hidup semasa atau sepeninggal beliau.

Oleh karenanya penulis merasa penting untuk menganalisa korelasi tema-tema tauhid dalam bab-bab kitab "Riyadhus sholihin," apa saja tema-tema kitab tersebut yang berkaitan dengan tauhid uluhiyah? Bagaimana korelasi tema-tema tersebut dengan tauhid uluhiyah dan korelasi dalil-dalil Al-Qur'an dan hadis dengan tema-tema yang dikonsep Imam Nawawi? Tulisan yang sederhana ini berusaha menjawab pertanyaan di atas, yang secara spesifik tentang Bab: Talqiin al-muhtadhar "laa ilaha illallah."

\section{B. METODE PENELITIAN}

Dalam hal ini penulis akan melakukan penelitian pustaka dan menggunakan metode penelitian kualitatif dengan pendekatan analisa konten, maksudnya adalah menganalisa Bab: Talqiinal-muhtadhar "laa ilaha illallah," dan dalil-dalil yang disebutkan oleh Imam Nawawi dan penjelasan tentang korelasi bab yang dikonsep beliau beserta dalil-dalinya dengan tahuid Uluhiyah.

Adapun data yang akan dikaji adalah kitab "Riyadhus sholihin" karya Imam Nawawi yang ditahqiq oleh Syaikh Ali bin Hasan Al-Halabi, yang diterbitkan oleh penerbit "Dar Ibnu Al-Jauzi" pada tahun $1421 \mathrm{H}$, cetakan pertama, KSA. 
p-ISSN: $2339-2630$

e-ISSN: 2477-8001
Muhammad Nur Ihsan, Studi Korelasi Bab : Talqiinal-

Muhtadhar "Laa Ilaaha Illallah"

\section{HASIL DAN PEMBAHASAN}

\section{Biografi Singkat Imam Nawawi}

Nama dan nasab beliau: Yahya bin Abi Yahya Syaraf bin Murry bin Hasan fin Husain bin Muhammad bin Jum'ah bin Hizam Al-Hizami An-Nawawi. Kunyahnya: Abu Zakaria, gelarnya: Muhyiddin. Seorang Imam yang zuhud dan wara', ahli ibadah, banyak puasa dan kiyamullail, baca Al-Qur'an dan dzikir, memiliki akhlak mulia dan kepribadian yang baik. Seorang Alim Rabbani yang bermazhab Syafi'I, disepakati keilmuan dan keutamaannya, memiliki reputasi dan loyalitas tinggi kepada Al-Qur'an dan sunnah Nabi (Ibnu 'Aththaar, 2007: 39-40).

Beliau dilahirkan di desa Nawa, dekat kota Damaskus pada bulan Muharram, tahun $631 \mathrm{H} / 1233 \mathrm{M}$ dan wafat pada 24 Rajab $676 \mathrm{H} / 1277 \mathrm{M}$, kedua tempat tersebut kemudian menjadi nisbat beliau An-Nawawi Ad-Dimasyqi (Ibnu 'Aththaar, 2007: 42-43).

Imam An-Nawawi salah seorang ulama yang sangat produktif, telah meninggalkan banyak karya ilmiah yang bermanfaat lagi terkenal dalam berbagai bidang keilmuan yang jumlahnya sekitar empat puluh kitab, dalam bidang hadits, fiqih, bahasa, akhlak dan lain-lain (Ibnu 'Aththaar, 2007: 70-85). Kendati kosentrasi beliau dan minat utamanya adalah Fiqih dan hadits, akan tetapi beliau adalah sosok ulama yang memiliki peran besar dalam menjelaskan tauhid uluhiyahdalam kitab yang menjadi tema penelitian ini. Hal ini insyallah akan menjadi bukti kebenaran akidah beliau tentang tauhid uluhiyah sebagaimana yang diyakini oleh Ahlussunnah wal Jama'ah.

\section{Pengertian Tauhid Uluhiyah dan Talkin}

Sebelum dijelaskan korelasi Bab: Talqiinal-muhtadhar "laa ilaha illallah" dengan Tauhid Uluhiyah, perlu dijelaskan terlebih dahulu maksud dan hakikat Tauhid Uluhiyahdan maksud Talkin.

Perlu diketahui bahwa keimanan kepada Allah Ta'ala mencakup keyakinan kepada tiga macam tauhid yang tidak bisa dipisahkan (Sulaiman bin Abdullah, 1985: 33-36).

Pertama, Tauhid Rububiyah, yaitu meyakini bahwa Allah Ta'ala adalah Rabb alam semesta, yang menguasai, menciptakan dan yang memberi rizki, Dialah yang menciptakan dan mematikan, yang memiliki segala urusan dan ditangan-Nya seluruh kebaikan. 
Kedua, Tauhid Asmaa was Sifat, yaitu menyakini bahwa Allah Ta'ala memiliki Asmaul Husnaa (nama-nama yang terbaik) dan sifat-sifat yang maha sempurna, tidak ada yang serupa dengan-Nya.

Ketiga, Tauhid Uluhiyah, -inilah yang menjadi tema makalah ini-,maksudnya adalah: Meyakini bahwa Allah Ta'ala adalah Zat Yang Maha Esa yang berhak diibadati dengan benar dan diikhlaskan seluruh ibadah kepada-Nya, berupa perkataan dan perbuatan, lahir dan batin, tiada sekutu bagi-Nya. Inilah hakikat kalimat tauhid (Laa Ilaaha Illallah) karena (إله) dalam bahasa arab bermakna (معبود) "yang diibadati." dan ia adalah kandungan firman Allah Ta'ala dalam surat Al-Fatihah (1):4 :

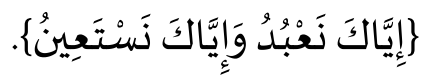

"Kepada Engkaulah kami beribadah dan kepada Engkaulah kami minta pertolongan."

Tauhid Uluhiyahadalah kewajiban manusia yang pertama dan hikmah utama penciptaan mereka, Allah berfirman dalam surat Adz-Dzaariyaat (51): 56:

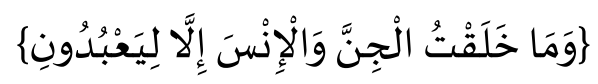

"Dan tidaklah Aku ciptakan Jin dan manusia kecuali untuk beribadah kepada-Ku."

Imam Nawawi mengomentari ayat di atas: "Ini adalah pernyataan yang jelas bahwa sesungguhnya manusia diciptakan untuk beribadah, maka hendaklah mereka memperhatikan tujuan penciptaan itu"(An-Nawawi, 1421: 40).

Ia adalah tujuan diutusnya para Rasul, sebagaimana yang dinyatakan dalam surat AlAnbiyaa' (21): 25:

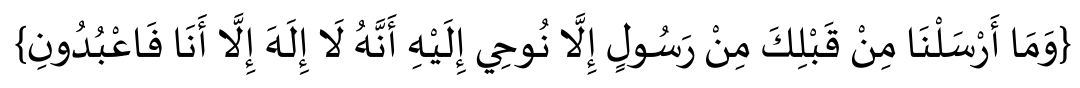

"Dan tidaklah Kami mengutus seorang rasulpun sebelum-mu kecuali Kami wahyukan kepadanya bahwa tiada Ilaa yang berhak diibadati secara benar kecuali Aku, maka Ibadatilah Aku." 
Perintah mengikhlaskan ibadah adalah tujuan diturunkan al-quran, sebagaimanayang dinyatakan dalam surat Az-Zumar (39): 2:

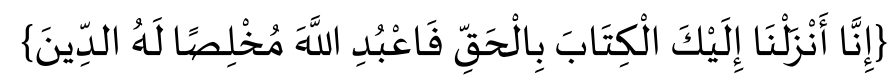

"Sesungguhnya Kami menurunkan kepadamu al-kitab (Al-Qur'an) dengan hak (benar), maka ibadatilah Allah dengan mengikhlaskan agama (ibadah) kepada-Nya."

Tauhid Uluhiyah dinamkan dengan Tauhid Ibadah, karena hakikat dan konsekuensinya adalah mengikhlaskan seluruh ibadah kepada Allah. Dinamakan dengan Tauhid Al-Iraadah, karena landasannya adalah menginginkan wajah Allah, pahala dan karunia-Nya dalam beramal, dinamakan dengan Tauhid Al-Qashd, karena landasannya adalah keikhlasan niat yang memestikan keikhlasan beribadah kepada Allah semata, dan dinamakan juga dengan Tauhid Al-'amal (amalan), karena landasannya adalah ikhlas beramal kepada Allah semata (An-Nawawi, 1421: 38).

Adapun Al-Muhtadhar adalah orang yang didatangi oleh para malaikat yang dipimpin oleh malaikat maut untuk mencabut nyawanya (Al-Utsaimin, 1426: IV/507). Adapun talkin adalah membacakan kalimat Laa Ilaha illallah perlahan-lahan ditelinganya, semoga kalimat tersebut yang menjadi akhir perkataannya. Dan kalimat Laa Ilaha illallah dinamakan dengan kalimat tauhid, karena hakikat kandungannya adalah keikhlasan ibadah kepada Allah yang merupakan hakikat tauhid, oleh karenanya dinamakan juga dengan kalimat ikhlas, dan keikhlasan ibadah kepada Allah adalah maksud dari tauhid Uluhiyah. Dari sisi ini jelaskan korelasi antara Bab: Talqin Muhtadhar: Laa Ilaha illallah dengan Tauhid Uluhiyah.

Adapun Talkin adalah membisikkan (menyebutkan) kalimat syahadat "Laa Ilaaha Illallah" dekat orang yang hendak meninggal, demikian dijelaskan dalam (KBBI), makna ini juga sesuai denganapa yang dijelaskan oleh para ulama tentang maksud Talqiin al-mayyit (AlBarkati, 2002: 62).

\section{Studi Korelasi Bab: Talqiin Al-Muhtadhir"La Ilaaha illallah" Dengan Tauhid Uluhiyah dan Korelasi Teks-Teks Hadis Dengan Bab Tersebut}

Dalam bab ini, Imam An-Nawawi rahimahullah membawakan dua hadis yang menjelaskan hukum mentalkinkan seorang yang sedang menghadapi sakaratulmaut. 
Adapun korelasi antara bab ini dengan tauhid uluhiyah sangat nyata sekali, karena kalimat yang ditalkinkan kepada yang sendang menghadapi kematian (Al-Muhtdhar) adalah kalimat Laa Ilaaha Illallah yang dinamakan dengan kalimat tauhid atau kalimat ikhlas, karena kandungannya adalah mentauhidkan Allah dalam seluruh ibadah dan itulah yang dimaksud dengan keikhlasan.

Adapun kedua hadis tersebut sebagai berikut:

Pertama: Hadis Mu'adz bin Jabal radhiyallah anhu yang diriwayatkan oleh Abu Daud (no.3116) dan Hakim (no.1299) dengan sanad shohih, Nabi shalallahu'alaihi wasallam bersabda:

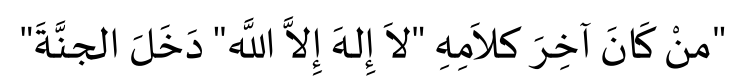

“Barangsiapa akhir perkataan (didunia) "Laa Ilaaha Illallah” niscaya ia masuk Surga."

Hadis ini menjelaskan bahwa barangsiapa yang akhir perkataannya tatkala menghadapi kematian adalah kalimat Tauhid, maka ia mendapatkan jaminan masuk Surga, karena ia meninggal dalam keadaan beriman, dan Surga hanya dimasuki oleh orang-orang yang beriman. Dan sebagaimana yang telah diutarakan bahwa kandungan kalimat Laa Ilaaha Illallah" adalah keikhlasan ubudiyah kepada Allah Ta'ala, dan itulah yang dimaksud dengan Tauhid Uluhiyah. Hal ini menjelaskan keutamaan Tauhid Uluhiyah dan kalimat Tauhid yang merupakan kunci untuk masuk Surga.

Adapun seseorang yang meninggal bukan di atas tauhid ini, akan tetapi mati dalam keadaan syirik, maka diharamkan Surga bagainya, sebagaimana yang dijelaskan oleh Allah dalam Al-Qur'an:

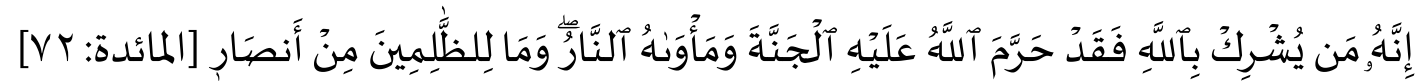

"Sesungguhnya barangsiapa yang berbuat syirik kepada Allah maka sungguh Allah haramkan Surga bagi-Nya dan tempatnya adalah neraka, dan tidak penolong bagi orang-orang yang berbuat dzolim (kesyirikan)."

Hadis di atas menjelaskan tentang keagungan tauhid dan kemuliannya, dengan demikian jelaskan korelasinya dengan tauhid uluhiyyah.

Kedua: Hadis Abu Sa'id Al-Khudri radhiyallah anhum yang diriwayatkan oleh Imam Muslim (no.916) dan dari Abu Hurairah radhiyallah ‘anhu (No. 917), Nabi shalallahu'alaihi wasallam bersabda: 
p-ISSN: 2339-2630

e-ISSN: $2477-8001$
Muhammad Nur Ihsan, Studi Korelasi Bab : TalqiinalMuhtadhar "Laa Ilaaha Illallah"

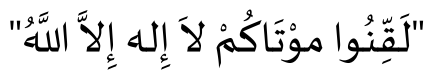

Talkilkanlah orang yang sedang menhadapi kematian dinatara kalian (kalimat): Laa Ilaaha Illallah.”

Imam Nawawi menjelaskan makna hadis ditas, maksud (موتاكم) adalah orang yang sedang menghadapi kematian, bukan orang yang telah mati, maksudnya: ingatkan ia dan bisikkan kepadanya kalimat Laa Ilaaha Illallah supaya kalimat yang mulia ini menjadi akhir ucapannya, sebagaimana yang tertera dalam hadis di atas (Nawawi, 1392: VI/219). hal ini menjelaskan korelasi yang nyata antara hadis dengan tauhid Uluhiyah, karena kandugan kalimat tauhid adalah keikhlasan ubudiyah kepada Allah Ta'ala.

Hadis ini juga menjelas bahwa hukum mentalkin orang yang sedang dalam menghadapi kematian adalah perkara yang disyariatkan, dan ulama telah sepakat tentang hal itu (Nawawi, 1392: VI/219).

\section{KESIMPULAN}

Setelah penjelasan di atas dan analisa terhadapdua hadis yang dibawakan oleh Imam Nawawi dalam Bab: Talqin al-muhtadhar "Laa Ilaaha Illallah", serta korelasinya dengan tauhid Uluhiyah, maka ada beberapa kesimpulan yang bisa ditarik dari analisa tersebut:

1. Kitab Riyadhus Sholihin bukan sekadar kitab hadis yang berbicara tentang tarqiib watarhiib dan tazkiyatun nufus semata, tetapi juga mengandung materi-materi akidah dan tauhid.

2. Kejelian Imam Nawawi dalam mengonsep bab-bab kitab tersebut dan memilih dalildalil yang tepat dan berkaitan dengannya.

3. Korelasi antara dua hadis yang dibawakan beliau dengan Bab: Talqin al-muhtadhar "Laa Ilaaha Illallahsangat jelas.

4. Korelasi antara Bab: Talqin al-muhtadhar "Laa Ilaaha Illallah" dengan tauhid Uluhiyah sangat nyata dan erat sekali, karena Laa Ilaaha Illallahadalah kalimat tauhid yang hakikatnya adalah kewajiban mengikhlaskan ibadah kepada Allah Ta'ala, itulah maksud tauhid uluhiyah. 
p-ISSN: $2339-2630$

e-ISSN: $2477-8001$
Muhammad Nur Ihsan, Studi Korelasi Bab : Talqiinal-

Muhtadhar "Laa Ilaaha Illallah"

\section{E. DAFTAR PUSTAKA}

Al-Utsaimin, Muhammad bin Sholeh, Syarah Riyadhis shalihin, cet. Dar Al-Wathan, Riyadh, $1426 \mathrm{H}$.

As-Sa'di, Abdurrahman bin Nashir, Taisir al-karim ar-rahman fii tafsir kalam al-mannan, cet. Muassasah Ar-Risalah, Beirut, 2000.

Abdurrahman bin Hasan, Fathul Majid li syarh kitab at-tauhid, cet. Dar Alam al fawaid, K S A.

Abu Daud, Sulaiman bin Asy'ats, Sunan Abi Daud, Tahqiq Muhammad Muhyiddin Abdulhamid, cet. Al-maktabah al-'Ashriyah, Beirut.

At-Tirmizi, Muhammad bin Isa, Sunan At-Tirmizi, Tahqiq Ahmad Syakir, Muhammad Fuad Abdulbaqi, cet. Mathba'ah Mudthafa Al-babi Al-Halabi - Mesir, 1975.

An-Naisaburi, Muslim bin Hajjaj, shohih Muslim (Al-Musnad ash-shahih al mukhtashar bi naqli al-'adl ila Rasulillah shalallahu'alaihi wasallam.) Tahqiq Muhammad Fuad Abdulbaqi, cet. Dar ihya at-turats al-arabi, Beirut.

Ibnu Hajar, Fathulbari Syarh shahih Al-Buhkari, cet. Dar Al-Ma'rifah, Beirut, 1379.

Ibnu Qoyyim, Madarij as- salikin, cet. Dar ak-kitab al-‘arabi, Beirut, 1996.

Ibnu 'Aththaar, Tuhfatut Thalibin fii Tarjamah al imam An-Nawawi Muhyiddin, tahqiq: Masyhur Bin Hasan Alu Salman, Yordania, Ad-Dar Al-Atsariyah, cet.1, 2007.

Nawawi, Muhyiddin bin Syaraf,Riyadhus sholihin, Tahqiq Syaikh Ali bin Hasan Al-Halabi, Dar Ibnu Jauzi, cet. Pertama, KSA.1421.

Sulaiman bin Abdullah bin Abdulwahhab, Taisiiril 'Azizil Hamid fii Syarhi Kitabit tauhid, , Beirut: Al-Maktab Al-Islami, cet. keenam. 1985.

Muhammad Amimum al Ihsan al Barki, At-Ta'riifaat al-fiqhiyyah, Beirut, Daar al kutub Alilmiyah, cet. Pertama. 2002.

Wikipedia, http://id.m.wikipedia.org/wiki/An-Nawawi. 